East African Medical Journal Vol. 86 No. 1 January 2009

EMOTIONAL AND BEHAVIOURAL DISORDERS IN HIV SEROPOSITIVE ADOLESCENTS IN URBAN UGANDA

S. Musisi MBChB., D. Psych. (Toronto), FRCP (C), Professor and Head, Department of Psychiatry, Makerere University Medical School, P. O. Box 7072, Kampala, Uganda and E. Kinyanda MBChB, MMed(Psy), PhD (NTNU), Research Manager, MRC/UVRl Uganda Research Unit on AIDS, Kampala, Uganda

Request for reprints to: Dr. S. Musisi, Department of Psychiatry, Makerere University Medical School, Kampala, P. O. Box 7072, Kampala, Uganda

\title{
EMOTIONAL AND BEHAVIOURAL DISORDERS IN HIV SEROPOSITIVE ADOLESCENTS IN URBAN UGANDA
}

\author{
S. MUSISI and E. KINYANDA
}

\begin{abstract}
Objective: To investigate the emotional and behavioral problems of HIV sero-positive adolescents.

Design: A cross-sectional descriptive study.

Setting: A specialised HIV/ AIDS Health Care Centre, the Mildmay Centre, in Kampala, Uganda.

Subjects: Eighty two HIV sero-positive adolescents were consecutively enrolled for the study.

Results: Over half $(55.6 \%)$ of the subjects were females. They were mostly $(88.9 \%)$ under the age of 15 years, orphans $(\mathbf{9 7 . 6 \%})$ and stayed with non-parental relatives $(68.3 \%)$. Almost two thirds $(60.9 \%)$ of them were in the HIV/ AIDS clinical disease stage III or IV and were not on ARVs drugs. Forty two (51.2\%) of the subjects had significant psychological distress (SRQ-25 scores $\geq 6$ ) and $14(17.1 \%)$ had attempted suicide within the last 12 months. Their specific psychiatric disorders, made using ICD-10 criteria, were: Anxiety $45.6 \%$, depression $40.8 \%$, somatisation $18.0 \%$, seizures $8.4 \%$, mania $1.2 \%$ and HIV-associated progressive encephalopathy $4.8 \%$.

Conclusion: HIV/AIDS infection in adolescence was associated with considerable psychological problems and the presence of major psychiatric disorders. With the current increasing availability of effective antiretroviral therapy, many of these children are surviving into adolescence, thus calling for the development of adolescent friendly HIV medical and psychological support and treatment services in developing countries such as Uganda.
\end{abstract}

\section{INTRODUCTION}

The HIV / AIDS epidemic has ravaged sub-Saharan Africa since the 1980s and has spawned a secondary epidemic of HIV seropositive offsprings, mainly through mother- to-child transmission (1). In Uganda, a country with an estimated 1.5 million people living with HIV/AIDS, about $24 \%$ of them are children below the age of 15 years (2). Children infected of HIV are at greater risk for psychological disturbances due to both the direct effects of HIV infection on brain structures that are involved in the regulation of emotion, behaviour, and cognition, and the indirect effects related to coping with the wide range of medical, psychological, and social stressors, as well as the slow acquisition of skills and delayed developmental milestones (3). Previous studies largely carried out in Western countries have shown high rates of emotional and behavioural disturbances in children with HIV infection including attention-deficithyperactivity disorder, oppositional defiant disorder, and problems in social functioning compared to peers $(3,4)$. For example Bose et al $(4)$ in a study of 33 HIV sero-positive children, reported high levels of anxiety and behavioural problems.

HIV / AIDS is also associated with a multitude of psychosocial problems that may induce psychiatric disorder in the HIV infected child $(5,6)$. The psychosocial problems associated with HIV / AIDS in childhood include: chronic physical illhealth, orphanhood, frequent bereavements (parents and siblings), poverty, frequent home changes, frequent changes of primary care-providers, breaking up of sib-ships, stigmatisation, frequent school abscondonments, chronic pain and physical and sexual abuse $(5,6)$.

However, there is still a paucity of research highlighting the specific emotional and behavioral problems of HIV sero-positive adolescents in subSaharan African countries including Uganda and behavioural problems among HIV sero-positive adolescents as seen at a specialised HIV / AIDS health care centre. 


\section{MATERIALS AND METHODS}

Across-sectional study design was employed in which HIV sero-positive adolescents were consecutively recruited from the Child and Adolescent Clinic at the Mildmay Centre which is a specialised HIV / AIDS health care centre. The Mildmay Centre is a NonGovernmental Organisation Centre that provides treatment and psychosocial support to HIV / AIDS infected and affected persons, from the nearby urban centre of Kampala. HIV sero-positive adolescents and their parent(s) / guardian(s) were interviewed. However, this paper will only report on the results of the HIV sero-positive adolescents without the parent(s)/ guardian(s) results which will be published at a later date. The eligibility criteria were that they should be (i) HIV sero-positive and/or, met the WHO modified Africa's clinical diagnostic criteria for AIDS related complex or full blown AIDS (7), (ii) between the ages of 10-18 years, (iii) having their guardians / parent(s) as clients at the centre, and (iv) knowing their HIV serological status. Asample size of 85 was calculated using the Kish and Leslie formula for descriptive studies. Eighty two adolescents who met the inclusion criteria were recruited into the study over a nine weeks period. Those adolescents who did not know their HIV serological status or whose guardians / parents declined consent, or who, themselves did not consent, were excluded from the study.

Assessment instruments: The SRQ-25 was the initial screening tool used, and the cut-off point was threshold for psychological distress scores was SRQ score $\geq 6$. The screening tool used a structured questionnaire that assessed the following: sociodemographics, orphan-hood status (non-orphan or maternal, paternal or double orphan status), school performance, past sexual experience, and the HIV / AIDS associated clinical signs and symptoms using the WHO modified criteria for the diagnosis of AIDS in Africa (7). The second tool used was the WHO/ Self Report Questionnaire-25 (WHO/SRQ-25) (8). This instrument consisted of 20 items for measuring neurotic distress and five items for measuring probable psychosis. This items for measuring instrument was initially developed as a screening tool for use in primary care settings but has since then been widely used to estimate the prevalence of probable mental disorders/distress in community samples including in Africa (9).

Adolescents who had significant psychological distress and scored $\geq 6$ on the WHO/SRQ-25 instrument were referred to a psychiatrist for specific diagnostic assessment using a questionnaire based on the ICD-10 research diagnostic criteria (11). For the current study, the psychiatric disorders that were assessed included; depression, anxiety disorders, somatoform disorders, psychotic disorders, substance abuse as well as conduct and personality disorders (10). Suicidal ideation was also assessed.

Procedure: HIV sero-positive adolescents and their parent(s) / guardian(s) were consecutively interviewed for this study. During the study period of three months, with the help of the clinic nurse on each given clinic day, HIV -positive adolescents who knew their HIV serological status were identified. Their accompanying parents/guardians were then asked to proceed to a private room where they were told about the study. Their written informed consent was then obtained to participate in the study together with their child after explaining to them the study details by the research assistant. Assent was obtained from the adolescent to participate in the study. The research assistant administered the sociodemographic questionnaire to each parent/guardian followed by their corresponding HIV - positive adolescent. This questionnaire also recorded the family composition and structure as well as orphanhood status as maternal, paternal or double orphan or non-orphan. Finally on this questionnaire was also recorded the school performance, past sexual experience and the HIV/AIDS associated clinical signs and symptoms and stage using the WHO modified criteria for the diagnosis of AIDS in Africa (7) as well as any other illnesses. These physical illness characteristics, including the HIV clinical stage, were recorded from either the patient's records or by direct examination. Following this, the WHO SRQ-25 was then administered to each adolescent. Any adolescent who scored $\geq 6$ on the SRQ-25, was referred to the study psychiatrists (the authors) for a diagnostic psychiatric interview based on the ICD10 Research Diagnostic criteria (10) to denote the specific psychiatric diagnosis. Noinvasive procedures were done on any subject. All data were obtained by interview, examination of clinical record or by physical examination.

Ethical consideration: Ethical clearance was obtained from the Institutional Review Board of the Makerere University Faculty of Medicine through the Uganda Society of Health Scientists who provided the research grant, and the administration of Mildmay Centre. Informed consent was obtained from all study subjects who had attained the age of consent (18 years and above). For the minors (less than 18 years), the consent of their legal guardians/parents was sought and the adolescents voluntarily assented to participate in the study. All study subjects who were found to have significant psychological distress/illness were referred to the Mental Health Clinic of Uganda's National Referral Hospital at Mulago, Kampala. 


\section{RESULTS}

All the eighty two subjects who were recruited came from Kampala district (where the Mildmay Centre is located), and the neighbouring districts of Wakiso and Jinja. Their socio-demographic characteristics were as follows: there were 46 (55.6\%) females, thus giving a male to female ratio of $1: 1.3$. Eighty one $(98.8 \%)$ were single and had a mean (SD) age of 13.4 (1.8) years. The majority of subjects, $43(53.1 \%)$ were between the ages of 13 and 15 years, $29(35.8 \%)$ of them between 10 and 12 years and nine (11.1\%) between 16 and 18 years. Only sixty two $(75.6 \%)$ of the adolescents were in school. The reasons given for not attending school were either being sick most of the time $(40 \%)$ or not being able to afford school fees (30\%). However, $20 \%$ of the adolescents gave other reasons, such as poor academic performance (5\%), didn't want to go to school $(5 \%)$, parent/guardian refusal $(5 \%)$ or having no reason at all, one (5\%). Table 1 below summarises these socio-demographic characteristics.
The characteristics of the caregivers are shown in Table 2: Of the 82 adolescents, only two $(2.4 \%)$ still had both parents alive with $44(53.7 \%)$ having lost both parents, $23(28 \%)$ had lost their mother only and $13(15.9 \%)$ their father only, thus creating a $97.6 \%$ orphan-hood status in these HIV sero-positive adolescents. The cause of parental death was either known AIDS in $47.8 \%$ of mothers and $59.4 \%$ of fathers or presumed AIDS $(21 \%$ of mothers and $9 \%$ of fathers). Thus about $68.5 \%$ of the parental deaths were either AIDS or presumed AIDS given the described associated illnesses. For $28 \%$ of the fathers and $38.8 \%$ of the mothers the cause of death was not known to the adolescents.

Over one third $(43.9 \%)$ of these HIV/AIDSorphaned adolescents stayed with other relatives, 26.8\% with a single parent (usually a mother) and $24.4 \%$ with grand parents or substitutes three (3.7\%). Only one adolescent (1.2\%) still stayed with both parents and one $(1.2 \%)$ was married.

Table 1

Socio-demographic characteristics of the HIV sero-positive adolescents $(n=82)$

\begin{tabular}{lrc}
\hline Variable & No. & Frequency (\%) \\
\hline District of residence & & \\
$\quad$ Kampala (site of clinic) & 58 & 70.8 \\
Wakes & 23 & 28.0 \\
Jinja & 1 & 1.2 \\
Sex & & \\
Male & 36 & 44.4 \\
Female & 46 & 55.6 \\
Age in years & & \\
10-12 & 29 & 35.8 \\
13-15 & 43 & 53.1 \\
16-18 & 9 & 11.1 \\
Attendance at school & & 75.6 \\
Currently in school & 62 & 23.2 \\
Not in school & 19 & 1.2 \\
Never attended school & 1 & \\
Marital status & & 98.8 \\
Never married & 1 & 1.2 \\
Married/ Cohabiting & 1 & \\
\hline
\end{tabular}




\section{Table 2}

Family characteristics of the HIV sero-positive adolescents

\begin{tabular}{lcr}
\hline Variable & No. & $(\%)$ \\
\hline Status of the parents & 2 & \\
Both parents alive & 13 & 2.4 \\
Father dead & 23 & 15.9 \\
Mother dead & 44 & 28.0 \\
Both parents dead & & 53.7 \\
Cause of death of mother (n=67) & 32 & \\
Known AIDS & 16 & 47.8 \\
Presumed AIDS & 1 & 21.0 \\
Cancer & 26 & 1.5 \\
Don't know & 23 & 38.8 \\
Cause of death of father (n= 57) & 1 & 28.0 \\
Accident & 34 & 1.2 \\
Known AIDS & 36 & 59.4 \\
Presumed AIDS & 46 & 44.4 \\
Don't know & & 55.6 \\
Structure of family at home & 1 & \\
Stay with both parents & 22 & 1.2 \\
Stay with single parent & 20 & 26.8 \\
Stay with grandparent(s) & 36 & 43.9 \\
Stay with other relative(s) & 3 & 3.7 \\
Stay with non-relative & & \\
\hline
\end{tabular}

Table 3

HIV-infection risk sexual behaviour among HIV sero-positive adolescents

\begin{tabular}{lcc}
\hline Variable & No. & Frequency $(\%)$ \\
\hline Sexually active & 6 & 7.3 \\
Age (years) at first sexual experience $(\mathrm{n}=6)$ & & \\
5 & 2 & 33.3 \\
9 & 1 & 16.7 \\
10 & 1 & 16.7 \\
15 & 1 & 16.7 \\
Not known & 1 & 16.7 \\
HIV risk sexual behaviour $(\mathrm{n}=6)^{*}$ & & \\
More than one sexual partner & 4 & 66.7 \\
Victim of rape & 5 & 83.3 \\
Unprotected sex & 6 & 100.0 \\
Genital ulcers/ discharge & 1 & 16.7 \\
Rapist tendencies & 1 & 16.7 \\
\hline
\end{tabular}

* Some respondents had more than one disorder/ problem 
Table 3 shows their HIV infection risk awareness and sexual behaviour. Six (7.3\%) of the HIV sero-positive adolescents had at least one sexual experience with five $(83.3 \%)$ of them being girls. Of those six who had sexual experiences, the first sexual experience for two $(33.3 \%)$ had occurred as early as five years of age. For most, five $(83.3 \%)$, this was usually by the way of forced sex or rape in girls, but one boy had raped young girls in his neighbourhood. Consequent high risk HIV sexual behaviour was reported in this particular group (of the six adolescents with past sexual experience) with, four $(66.7 \%)$ reporting sex with more than one partner, six $(100 \%)$ having had unprotected sex and one $(16.7 \%)$ adolescent having had genital ulcers and discharge. Table 3 below shows the physical health status of the respondents and their WHO- HIV / AIDS clinical staging.

The general health of the adolescents showed stunted growth, multiple physical symptoms and advanced HIV clinical disease (Table 4). These symptoms included cough for more than one month but without evidence of TB in $60(73.2 \%)$ of them; forty four $(53.7 \%)$ had significant weight loss and had experience fever for more than one month, 41 $(50 \%)$ of greater than $10 \%$ of their previous weight.

Table 4

Physical illnesses and HIV/AIDS clinical stages of the HIV sero-positive adolescents

\begin{tabular}{lll}
\hline Variable & No. & Frequency (\%) \\
\hline HIV / AIDS clinical signs and symptoms* & & \\
Fever for more than one month & 41 & 50.0 \\
Weight loss (at least 10\% body weight) & 44 & 53.7 \\
Diarrhoea for one month or more & 14 & 17.1 \\
Cough for $\geq 1$ month (No evidence of TB) & 60 & 73.2 \\
Generalised pruritic dermatitis & 39 & 47.6 \\
Herpes zoster & 7 & 8.5 \\
Oral pharyngeal candidiasis & 12 & 14.6 \\
Chronic/aggressive ulcerative herpes simplex & 9 & 11.0 \\
Generalised lymphadenopathy & 9 & 11.0 \\
Kaposis Sarcoma & 0 & 0.0 \\
Pulmonary tuberculosis & 12 & 14.6 \\
Cryptococcal meningitis & 2 & 2.4 \\
HIV dementia & 4 & 4.9 \\
HIV non-specific somatic complaints* & & \\
Episodes of difficulty in breathing & 4 & 4.9 \\
Conjunctivitis & 3 & 3.7 \\
Generalised non-pruritic dermatitis & 11 & 13.4 \\
Physical retardation & 6 & 7.3 \\
Cardiac problems & 3 & 3.7 \\
Others & 7 & 8.5 \\
HIV / AIDS clinical stage & 1 & 1.2 \\
Stage 1 & 31 & 37.8 \\
Stage 2 & 48 & 58.5 \\
Stage 3 & 2 & 2.4 \\
Stage 4 & & \\
\hline
\end{tabular}

* Some respondents had more than one disorder/ problem 
In terms of staging, of their HIV/AIDS clinical disease the majority $50(60.9 \%)$ of respondents were in advanced HIV Clinical disease Stage III and IV. None of them were on antiretroviral medication.

A great number of adolescents had significant psychological distress and psychiatric disorders Table 5. The cut-off point for significant psychological distress used in this study was set at having a score of $\geq 6$ on the WHO-SRQ- 25 scale, a threshold similar to that used in Ethiopia, whose African socio-culture environment is similar to that of Uganda where this study was carried out (9).

Using the SRQ score cut-off of at least six for significant psychological distress, $42(51.2 \%)$ of these adolescents had above threshold scores (Table 5). Indeed $14(17.1 \%)$ had attempted suicide within the preceding 12 months, whereas $16(19.5 \%)$ had a life time attempted suicide. Twenty five
(30.5\%) had ever suffered features of psychosis in the past. Among those with above threshold psychological distress $(n=42)$ scores, the specific ICD10 psychiatric disorders were assessed using ICD-10 symptom checklists. The reported specific ICD-10 psychiatric disorders included anxiety disorders, $38(45.6 \%)$, depression, $34(40.8 \%)$, somatisation disorder, $15(18.0 \%)$, seizure disorder, seven $(8.4 \%)$, mania one $(1.2 \%)$ and HIV-associated Progressive encephalopathy (HIV-PE) four (4.8\%). On substances of abuse, two (2.4\%) used alcohol while two (2.4\%) used inhalants (aviation fuel).

It can be seen in Table 6 below that the factors that were significantly associated with psychological distress amongst the HIV sero-positive adolescents included age; the younger the adolescent was, the more likely he/she was to be psychologically distressed $(\mathrm{OR}=2.68 ; 95 \% \mathrm{C} 1=1.06-6.77 ; \mathrm{p}=0.03)$.

Table 5

Psychological distress, psychiatric illness and substance abuse among HIV sero-positive adolescents ( $n=82)$

\begin{tabular}{lcc}
\hline Variable & No. & Frequency (\%) \\
\hline $\begin{array}{l}\text { Psychological distress scores } \\
\text { (SRQ-25) }\end{array}$ & \\
0 & 10 & 12.2 \\
$1-3$ & 15 & 18.3 \\
$4-5$ & 15 & 18.3 \\
$\geq 6$ & 42 & 51.2 \\
Psychiatric diagnosis* & & \\
Anxiety & 38 & 45.6 \\
Depression & 34 & 40.8 \\
Somatisation disorder & 15 & 18.0 \\
Seizure disorder & 7 & 8.4 \\
HIV -PE* & 4 & 4.8 \\
Bipolar disorder (mania) & & 1.2 \\
Use of substances of abuse & 1 & 2.4 \\
Alcohol & 2 & 2.4 \\
Volatile inhalants (aviation fuel) & 2 & 17.1 \\
History of attempted suicide & & 19.5 \\
In the past 12 months & 14 & \\
In entire life- time & 16 & \\
\hline
\end{tabular}

* Some respondents had more than one disorder/ problem ${ }^{* *}$ HIV-PE $=$ HIV-associated progressive encephalopathy. 
Table 6

Factors associated with psychological distress in the HIV sero-positive adolescents $(n=82)$

\begin{tabular}{|c|c|c|c|c|c|c|c|c|c|}
\hline \multirow[t]{2}{*}{ Variable } & \multicolumn{2}{|c|}{ Total Number } & \multicolumn{2}{|c|}{$\begin{array}{l}\text { Non-Cases } \\
(\mathrm{SRQ}<6)\end{array}$} & \multicolumn{2}{|c|}{$\begin{array}{l}\text { Cases } \\
(S R Q \geq 6)^{* *}\end{array}$} & \multirow[t]{2}{*}{$\begin{array}{l}\text { Chi- } \\
\text { Square }\end{array}$} & \multirow[t]{2}{*}{ P-value } & \multirow[t]{2}{*}{$\mathrm{OR}(\mathrm{CI})$} \\
\hline & No. & $(\%)$ & No. & $(\%)$ & No & $(\%)$ & & & \\
\hline \multicolumn{10}{|l|}{ Age } \\
\hline $10-12$ & 29 & 34.8 & 19 & 22.8 & 10 & 12.0 & 4.32 & $0.037^{*}$ & $2.68(1.06-6.77)$ \\
\hline $13-18$ & 53 & 65.2 & 21 & 27.6 & 32 & 38.4 & 6.12 & $0.013^{*}$ & \\
\hline \multicolumn{10}{|c|}{ School attendance } \\
\hline In school & 62 & 75.6 & 32 & 38.4 & 24 & 28.2 & $4.94(1 \mathrm{df})$ & $0.026^{*}$ & $3.00(1.14-7.89)$ \\
\hline Out of school & 20 & 24.4 & 8 & 9.6 & 18 & 21.6 & & & \\
\hline \multicolumn{10}{|c|}{ Play sports at school } \\
\hline Yes & 36 & 43.2 & 26 & 31.2 & 10 & 12.0 & $14.11(1 \mathrm{df})$ & $0.000^{*}$ & $5.94(2.29-15.40)$ \\
\hline No & 46 & 55.2 & 14 & 16.8 & 32 & 38.4 & & & \\
\hline \multicolumn{10}{|c|}{ Academic grades $(n=62)$} \\
\hline Good & 27 & 43.6 & 21 & 33.7 & 12 & 28.6 & 2.513 & 0.113 & $2.12(0.84-5.34)$ \\
\hline Fair/poor & 35 & 56.4 & 19 & 30.7 & 23 & 37.1 & 0.74 & 0.389 & \\
\hline \multicolumn{10}{|c|}{ HIV-related physical symptoms } \\
\hline Yes & 65 & 79.3 & 26 & 31.7 & 39 & 47.6 & $9.675(1 \mathrm{df})$ & $0.002^{*}$ & $0.14(0.04-0.55)$ \\
\hline No & 17 & 20.7 & 14 & 17.1 & 3 & 3.6 & & & \\
\hline \multicolumn{10}{|c|}{ HIV status of the caretaker $(n=35)$} \\
\hline HIV Positive & 19 & 54.3 & 13 & 37.1 & 6 & 17.2 & 3.82 & $0.050^{*}$ & $6.50(1.52-27.6)$ \\
\hline HIV Negative & 16 & 45.7 & 4 & 11.4 & 12 & 34.3 & 4.50 & $0.034^{*}$ & \\
\hline \multicolumn{10}{|c|}{ Knowing HIV status of caretaker } \\
\hline Yes & 35 & 42.7 & 172 & 20.7 & 18 & 22.0 & $0.001(\mathrm{ldf})$ & 0.974 & $0.99(0.41-2.35)$ \\
\hline No & 47 & 57.3 & 23 & 28.0 & $24(2$ & 29.3) & & & \\
\hline
\end{tabular}

* Statistically significant association at $\mathrm{p} \leq 0.05$

${ }^{* *}$ Case $=$ Psychological distress defined as having SRQ score of $\geq 6$

The other factors associated with psychological distress were being out of $\operatorname{school}(\mathrm{p}=0.026 ; \mathrm{OR}=3.00$; 95\% CI $=1.14-7.89)$, not being able to play sports at school $(\mathrm{OR}=5.94 ; 95 \% \mathrm{CI}=2.29-15.40 ; \mathrm{p}=0.001)$, and the HIV - status of the caretaker $(\mathrm{OR}=6.50 ; 95 \% \mathrm{CI}$ $=1.52$-27; $\mathrm{p}=0.050$ ).

A history of having suffered rape almost attained statistical significance at Fischer's Exact test $(p=0.055)$.However, observableHIV-related physical signs and symptoms or the actual adolescents' knowledge of the HIV sero-status of their caregiver was not significantly associated with them being psychologically distressed. The other factors that were not significantly associated with psychological distress in the adolescent included; sex, tribe, religion, marital status, highest level of education, academic grades, presence of parents, person with whom the child was staying, birth order, use of substance of abuse, being sexually active, past suicide attempt, attendance of professional counselling and HIV clinical stage.

\section{DISCUSSION}

There were more female HIV sero-positive adolescents, with a male to female ratio of $1: 1.3$, and a mean age of 13.4 years $(S D=1.84)$. Higher HIV / AIDS prevalence rates have been variously reported in the Ugandan female youth with a male to female ratio of 1:6 reported in some studies $(2,5)$. The reason for this are varied such as girls being sought out for sex by older men. Nevertheless, this points to the higher vulnerability of the girl child to be infected with HIV / AIDS in Uganda(1). Only one of the adolescents was married and she was a female. This could be explained, first, by the fact that most $(88.9 \%)$ of our 
adolescent sample was aged below 15 years; and secondly it may suggest that these adolescents may have acquired their HIV / AIDS perinatally through mother-to-child transmission. This is in agreement with the reported prevalence of a 30\% mother-tochild transmission rate of HIV / AIDS often reported in Uganda $(1,11)$. The majority of the adolescents in this study acquired their HIV infection vertically and this seems to support the fact that $97.6 \%$ of them were orphans having lost a mother $(28 \%)$, a father $(15.9 \%)$ or both parents $(53.7 \%)$, due to "known or presumed AIDS" in $68 \%$ of the death cases. At the time that this study was conducted, HIV / AIDS was a terminal illness as the majority of Ugandans had no access to anti-retroviral medication - a situation which has since changed.

Five per cent of theHIV sero-positiveadolescents, all girls had experienced coercive sexual abuse in the form of rape - one of the saddest aspects of this study. The perpetrators of the sexual abuse was a father in one case, a stranger in another case, street boys in the third case and a lesbian digital penetration and manipulation of one of the girls genitalia in one case. Following these first sexual encounters, these abused children then went on to have other sexual encounters but of an unusually high risk nature. They all engaged in unprotected sex, had had multiple sexual partners $(66.7 \%)$,or had ever had genital ulcers and discharge (16.7\%). In addition' one of them (the male adolescent) was reported to have had rapist behaviour targeting young girls in the neighbourhood. Such findings of sexual abuse in these very young HIV / AIDS sero-positive children were very distressing to them. Except for the boy, who raped girls in his neighbourhood, no legal (or child-protective) action had been instituted for the abusers. This pointed to a need for the strengthening and enforcement of child protection laws, particularly for vulnerable groups such as orphans as sexual abuse by adults has often been reported in orphans (12).

Slightly over fifty per cent (51.2\%) of the HIV sero-positive adolescents in this study had above threshold psychological distress. This figure is equivalent to that of $53 \%$ for a psychiatric diagnosis reported by Pao and colleagues (13) for an adolescent HIV sero-positive population in the U.S. In the present study, it is noteworthy that it was mainly the school associated factors, such as playing school sports, being unable to go to school and age, that were the most likely to be associated with psychological distress. This is perhaps not surprising given the importance attached to education and thus school attendance in Uganda. Indeed it was the older adolescents who were more likely to be distressed by these school related factors as they affected their social adjustment.

The caretakers' status was associated with significant psychological distress in the adolescent. This finding did not come as a surprise as research in this area has repeatedly shown that adult HIV sero-positivity is itself associated with psychological distress and that psychological distress in parents is a risk factor for emotional and behavioural problems in their children (14). However the adolescents' knowledge of his/her caretaker HIV sero-status was in itself not associated with more psychological distress in the adolescent. The reasons for this observation are not immediately obvious but may lie in an accepting environment at home to the HIV sero-positive adolescent, hence less felt-stigma. The HIV sero-positive adolescent in a household where the caretaker and the other children know the HIV sero-status of the caretaker may lessen the impact or negative affect and stigma from other persons. On the other hand in the household where the caretaker's HIV sero- status is not known, the environment in that home may be more likely to be less accepting and more secretive, thus causing more distress to the adolescent.

In the currentstudy the most reported psychiatric disordersin the HIV-positive adolescents were anxiety (45.6\%) and depression (40.8\%). Pao et al (13) in their HIV sero-positive adolescent study reported a rate for depressive disorder to be $44 \%$. Scharko (15) in a meta-analysis of papers on psychiatric disorders in the context of HIV/AIDS gave as the most commonly reported psychiatric disorders, attention deficit hyperactivity $(28.6 \%)$, anxiety $(24.3 \%)$, and depression $(25 \%)$. Manic disorder was also reported among respondents in this study. Nakimuli-Mpungu et al (16) in Uganda described a manic syndrome secondary to HIV/AIDS that differs significantly from primary mania. In the present study, almost $20 \%$ of the adolescents had attempted suicide at one time or another. Suicidal behaviour is common in HIV / AIDS infected persons and has been reported by various workers and usually occurs in either the initial stages (stage I) of the illness or in the terminal stages (stages III and IV) $(17,18)$.

As a limitation of this study, firstly the sample used was drawn from a specialised urban clinic at Mildmay Centre, yet the majority of HIV sero-positive adolescents in Uganda are found in rural areas. This raises the question of the generalisability of these findings to the wider population of HIV seropositive adolescents in Uganda. Secondly, only those adolescents who knew their HIV serological status were recruited in the study. This left out those other adolescents whose parents / guardians had not yet disclosed to them their HIV serological status. This was a major limitation in the study as there was no "Disclosure Clinic" at the Mildmay Centre. At the time of the study there was no institutional programme at the clinic to assist parents / guardian disclose to the adolescent's their HIV serological status. This was left to the parents / guardians who often-times were uncomfortable and didn't know how to do it. 
In conclusion, HIV / AIDS was associated with considerable emotional and behavioural problems in adolescence. The most prevalent psychiatric disorders in this sub-population were anxiety and depression. The clinical implication of this study is that there is need to make HIV/AIDS support services sensitive to the needs of HIV sero-positive adolescents. Furthermore, there is need to increase access to antiretroviral medication (ARVs) to children and adolescents who are in advanced stages of the HIV disease to relieve their physical and psychological suffering. Lastly, governments should set up mechanisms to enforce child protection laws and mechanisms such as a Special Children's Protection Agency for vulnerable children including orphans and those with HIV / AIDS.

\section{ACKNOWLEDGEMENTS}

To our respondents, both the children and parents from the Mildmay Centre, Uganda. Thanks also go to the management and staff of the Mildmay Centre for their cooperation during this study. We would also like to thank the Uganda Society of Health Scientists for the grant that funded this study.

\section{REFERENCES}

1. Guay, L., Musoke, P., Fleming, T., et al. Intrapartum and neonatal single dose nevirapine compared with Zidovudine for prevention of Mother- To-Child Transmission of HIV -1 in Kampala, Uganda. HIVNET 012 Randomised trial. Lancet. 1999; 354: 795-802.

2. Uganda AIDS Commission. Twenty years of HIV/ AIDS in the world: Evaluation of the epidemic and response in Uganda. Kampala, Uganda 2001.

3. Bachanas, P. J., Kullgren, K. A., Schwartz, K. S., et al. Predictors of psychological adjustment in school-age children infected with HIV. J. Pediatr. Psychol. 2001; 26: 343-352.

4. Bose, S., Moss, H., Brouwers, P., Pizzo, P. and Lorion, R. Psychological adjustment of HIV-infected school age children. J. Dev. Behav. Pediatr. 1994; 15: 26-33.

5. Musisi,S., Kinyanda, E., Nakasujja, et al: A comparison of the behavioural and emotional problems of orphans Vs non-orphans in Uganda. Afr. Hlth. Sci. J. 2007; 4: 202-213.
6. Close, K. and Rigamonti A. X. Psychosocial aspects of HIV/AIDS: Children and adolescents. In: HIV curriculum for the health professional. Baylor International, Pediatric AIDS Initiative.

7. Mugerwa, R., Windy-Wiski, R. and Okware, S. Assessment of a Provisional WHO clinical case definition of HIV related illness in the referral hospital of Uganda. Proceedings of the Second International Symposium on AIDS and Associated Cancers in Africa Oct 7-9 Naples, Italy, 1987.

8. WHO. A User's guide to the Self-Reporting Questionnaire, (SRQ.) Geneva, Switzerland, 1994.

9. Kebede, D., Alem, A. and Rashid, E. The prevalence and socio-demographic correlates of mental distress in Addis Ababa, Ethiopia. Acta Psychiatr. Scand. 1999; 100: 5-10.

10. WHO. The 1CD-10 Classification of Mental and Behavioural Disorders. Research Diagnostic Criteria Geneva, Switzerland, 1992. 15.

11. Epstein, L. G., Sharer, L. R. and Oleske, J. M.Neurologic manifestations of Human Immunodeficiency Virus Infection in Children. Paediatr. 1986; 78: 678-687.

12. Wakhweya, A., Kateregga, C., Konde-Lule, J., et al. Situation Analysis of Orphans in Uganda: Draft Version Report. Centre for International Health, Boston University, 2002.

13. Pao, M., Lyon, M., D'Angelo, L. J., et al. Psychiatric diagnosis in adolescents seropositive for the human immunodeficiency virus. Arch. Pediatr. Adolesc. Med. 2000; 154: 240- 244.

14. Eisenhower, M. E., Hanson, S. G., Riley, A. W. and Juon, H. Maternal psychological distress: adult sons and daughters mental health and educational attainment. J. Amer. Acad. Child Adolesc. Psychiatr. 2003; 42: 1108-1115.

15. Scharko, A. M. DSM psychiatric disorders in the context of pediatric HIV / AIDS. AIDS Care. 2006; 18: 441-445.

16. Nakimuli-Mpungu, E., Musisi, S., KiwuwaMpungu, S. and Katabira, E. Primary mania versus HIV related secondary mania in Uganda. Amer. J. Psychiatr. 2006; 163: 1349 -1354.

17. Kaleeba, T. B., Tegegne, T. and Alem, A. Childhood behavioural disorders in Ambo district, Western Ethiopia I prevalence estimates. Acta. Psychiatr. Scand. 1999; 100: 92-97.

18. Kinyanda, E, Hjelmeland, H. and Musisi, S. Negative life events associated with deliberate self-harm in an African population in Uganda. Crisis, 2005; 26: $4-11$. 